\title{
RANCANGAN APLIKASI PENJUALAN HEWAN QURBAN DAN AQIQAH PADA RAISHA FARM GUNA MEMPERLUAS AREA PENJUALAN
}

\author{
Wulandari $^{{ }^{*}}$, Indiarto Prayoga ${ }^{2}$, Bayu Hasmoro Putro ${ }^{3}$, Resita Sri Wahyuni ${ }^{4}$ \\ 1,2,3,4 Fakultas Teknologi Informasi, Sistem Informasi, Universitas Budi Luhur, Jakarta, Indonesia \\ Email: ${ }^{1 *}$ Wulandari@budiluhur.ac.id, ${ }^{2} 1612501187 @$ student.budiluhur.ac.id, ${ }^{3} 1612502060 @$ student.budiluhur.ac.id, \\ ${ }^{4} 1612500924 @$ student.budiluhur.ac.id \\ (*: coressponding author)
}

\begin{abstract}
Abstrak - Raisha Farm ialah usaha perorangan yang memperjual belikan hewan untuk keperluan Qurban maupun Aqiqah, hewan yang dijual yaitu kambing, domba dan sapi, penjualan hewan untuk kebutuhan qurban akan meningkat pada saat hari raya idul adha yaitu perayaan agama islam. Saat ini perkembangan teknologi setiap harinya mengalami perkembangan yang sangat pesat, dalam memasuki era perdangangan bebas, setiap bidang usaha akan saling bersaing dengan ketat agar tidak tersaingi oleh pesaingnya. Untuk itu Raisa Farm perlu melalukan inovasi agar usahanya dapat dikenal oleh masyarakat luas, untuk itu perlu dibuatkan sebuah aplikasi berbasis web agar masalah terssebut terselesaikan dengan tujuan memperluas area penjualan hewan ternak untuk keperluan qurban maupun aqiqah. Metode yang digunakan penulis untuk mengembangan penelitian ini adalah prototype, tahapan yang digunakan yaitu pengumpulan data, perancangan sistem dan evaluasi. Untuk memodelkan sistem penulis menggunakan UML, sedangkan untuk mengembangkan aplikasi peneliti menggunakan PHP dan Mysql. Untuk menguji sistem peneliti menggunakan Black-Box Testing untuk mengevaluasi keberhasilan program, pada akhir penelitian ini dibangun sistem yang memudahkan pelanggan untuk memesan baik online maupun secara langsung. Sehingga diharapkan dengan adanya sistem yang telah dibangun raisha farm dapat memperluas area penjualan tidak hanya disekitaran daerahnya saja tetapi dapat menjangkau masyarakat luas. Dengan meningkatnya are penjualan tentunya akan meningkatkan omset perusahaan.
\end{abstract}

Kata Kunci: penjualan, aplikasi, hewan ternak, qurban, aqiqah

Abstract- Raisha Farm is an individual business that trades animals for the purposes of Qurban and Aqiqah, the animals sold are goats, sheep and cows, the sale of animals for qurban needs will increase during Eid al-Adha, which is a celebration of the Islamic religion. Currently, the development of technology every day is experiencing very rapid development, in entering the era of free trade, every business field will compete with each other tightly so as not to be rivaled by its competitors. For this reason Raisa Farm needs to innovate so that its business can be known by the wider community, for that it is necessary to create a webbased application so that the problem is resolved with the aim of expanding the area for selling livestock for qurban and aqiqah purposes. The method used by the author to develop this research is a prototype, the stages used are data collection, system design and evaluation. To model the system the author uses UML, while to develop the application the researcher uses PHP and Mysql. To test the research system using Black-Box Testing to evaluate the success of the program, at the end of this study a system was built that made it easy for customers to order both online and in person. So it is hoped that with the system that has been built Raisha Farm can expand the sales area not only around the area but can reach the wider community. With the increase in sales area will certainly increase the company's turnover.

Keywords: sales, application, livestock, qurban, aqiqah

\section{PENDAhULUAN}

Idul Adha merupakan perayaan keagamaan bagi umat islam, pada saat idul adha umat islam memotong hewan ternak seperti kambing, sapi dan domba untuk berqurban sebagai wujud syukur manusia kepada Tuhan. Sedangkan Aqiqah dalam hukum islam bagi kelahiran anak laki-laki diwajibkan memotong dua hewan kambing, sedangkan untuk anak kelahiran anak perempuan satu hewan kambing, daging aqiqah tersebut di berikan kepada fakir miskin dan anak yatim[1]. Hewan qurban dan Aqiqah didapat dari peternakan, peternakan adalah salah satu cabang pertanian yang berfokus dalam budidaya hewan [2]. Hewan ternak selain digunakan untuk keperluan keagamaan juga banyak dinikmati untuk konsumsi [3] sendiri.

Bidang usaha yang diteliti pada penelitian ini yaitu usaha yang menjual hewan untuk keperluan qurban maupun aqiqah yaitu kambing, domba dan sapi. Saat ini persaingan usaha antar penjualan ternak sudah semakin banyak, sehingga dibutuhkan inovasi bagi pelaku usaha agar usaha mereka dapat dikenal dan dapat memperluas area penjualan. Teknologi yang semakin berkembang saat ini dirasa sanggat perlu untuk melakukan persaingan bisnis, banyak pengusaha yang saat ini sudah membangun hubungan jangka panjang dengan para pelangganya[4][5], hubungan jangka panjang tersebut diberikan dengan memberikan kemudahan dalam bertransaksi. Kemudahan transaksi ini sangat dibutuhkan oleh masyarakat pada era ini [6], salah satunya kemudahan dalam melakukan pemesanan secara online sehingga pelanggan tidak perlu datang untuk melakukan pemesanan. 
Beberapa penelitian pendahulu yang melakukan penelitian tentang pembuatan aplikasi penjualan qurban maupun Aqiqah yaitu penelitian oleh R. Pakaya, A. R. Tapate, and S. Suleman dengan masalah yang terjadi kesulitan dalam melakukan penjualan kepada pelanggan terkait informasi harga dan jumlah hewan yang tersedia. Hasil akhir penelitian tersebebut dibangunya sebuah aplikasi online berbasis web dan juga android yang terintegrasi antara penjual dan pembeli, untuk mempermudah para keduanya dalam melakukan penjualan dan pembelian[1]. Penelitian yang dilakukan oleh I. Oktaviani, and R. S. Lilik masalah yang terjadi yaitu kegiatan penjualan maupun pemesanan maupun promosi belum dilakukan secara online dan terintegrasi dengan sosial media. Hasil dari penelitian ini yaitu di banguny siste informasi penjualan berbasis ecommers, yang nantinya akan digunakan kedua belah pihak baik konsumen maupun produsen [6] dalam melakukan transaksi.

\section{METODE PENELITIAN}

Dalam meneliti, penulis memakai metode prototype, metode prototype ini bukan sebuah sistem yang dibuat secara utuh, melainkan sesuatu yang nantinya akan diuji dan dapat diubah Kembali sesuai kebutuhan[7]. Metode Prototype sendiri sudah banyak dipakai oleh pengembangan dalam mengembangkan perangkat lunak. Tujuan metode ini adalah mempermudah interaksi pengembangan dan pelanggan dalam membuat sistem[8]. Dalam penelitian ini penulis melakukan pengumpulan data, perancangan sistem dan Evaluasi. Langkah penelitian yang dilakukan penulis ditunjukan pada gambar 1 .

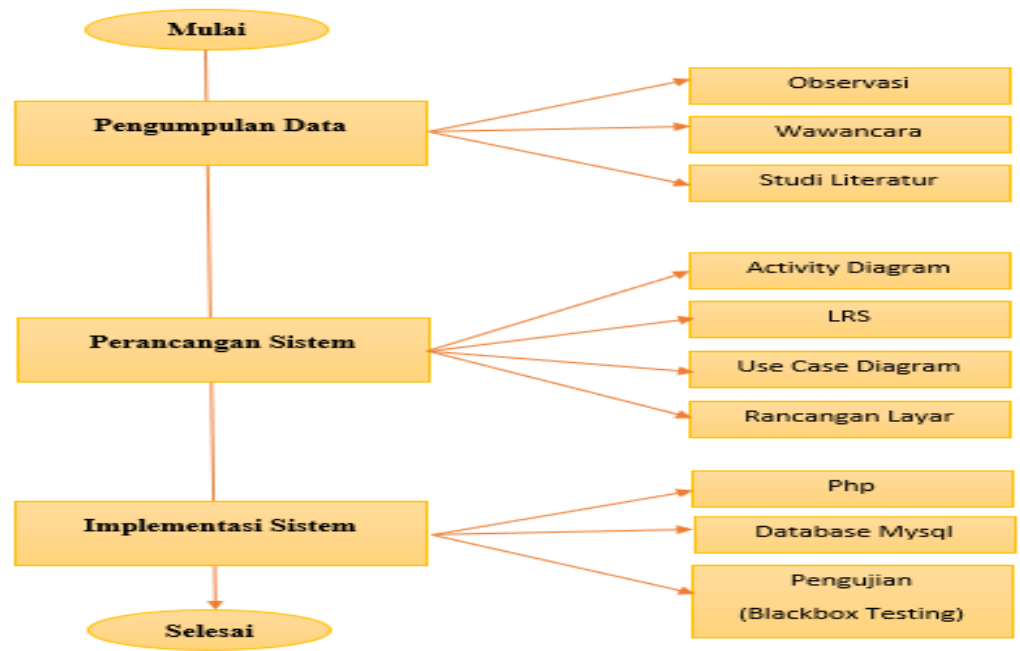

Gambar 1. Langkah-langkah Penelitian

Keterangan:

\section{a. Pengumpulan Data}

Penulis mengamati langsung proses yang berjalan pada perusahaan atau biasa disebut observasi, dilanjutkan dengan kegiatan wawancara dengan cara bertanya langsung ke pihak yang terkait. Setelah kegiatan wawancara dilakukan penulis akan melakukan Analisa dokumen yaitu dengan menganalisa dokumen yang terkait dengan penelitian ini dan dengan melakukan studi literatur yaitu mencari beberapa buku atau jurnal ilmiah terkait dengan topik yang sedang diteliti yang nantinya akan digunakan sebagai pendukung dalam penelitian ini.

\section{b. Perancangan Sistem}

Dalam proses perancangan sistem peneliti menganalisis dokumen dan data yang didapat pada tahapan pengumpulan data, berdasarkan hasil analisis kemudian diimplementasikan kedalam UML diantaranya Activity Diagram, Use Case Diagram, LRS dan Tampilan Layar.

\section{c. Implementasi Sistem}

Dalam Tahapan Implementasi, peneliti mendevelop menggunakan Php dan database Mysql. untuk pengujian sistem peneliti menggunakan Black-Box Testing yaitu menjalankan dan menginputkan pada sistem yang telah dibuat, dari inputan itu dapat dilihat apakah program yang dibuat terdapat error dan isian yang masih kosong akan memberikan pesan agar field di isi lengkap[4]. Tujuan dari Evaluasi untuk mengetahui keberhasilan sistem [7] yang sedang di bangun. 


\section{HASIL DAN PEMBAHASAN}

\subsection{Activity Diagram}

Berikut ini merupakan bisnis proses usulan pada Raisha Farm yang terdiri atas login, pemesanan Qurban, pemesanan Aqiqah, Pembayaran, pengiriman dan pembuatan laporan.

\section{a. Proses Login}

Pelanggan membuka website Raisha Farm, lalu melakukan login untuk mengakses website. Jika pelanggan belum memiliki akun, diwajibkan daftar terlebih dahulu dengan mengisi form pendaftaran berisi nama, alamat, nomor telepon agar dapat melakukan transaksi. Activity Diagram proses login di tunjukan pada Gambar 2:

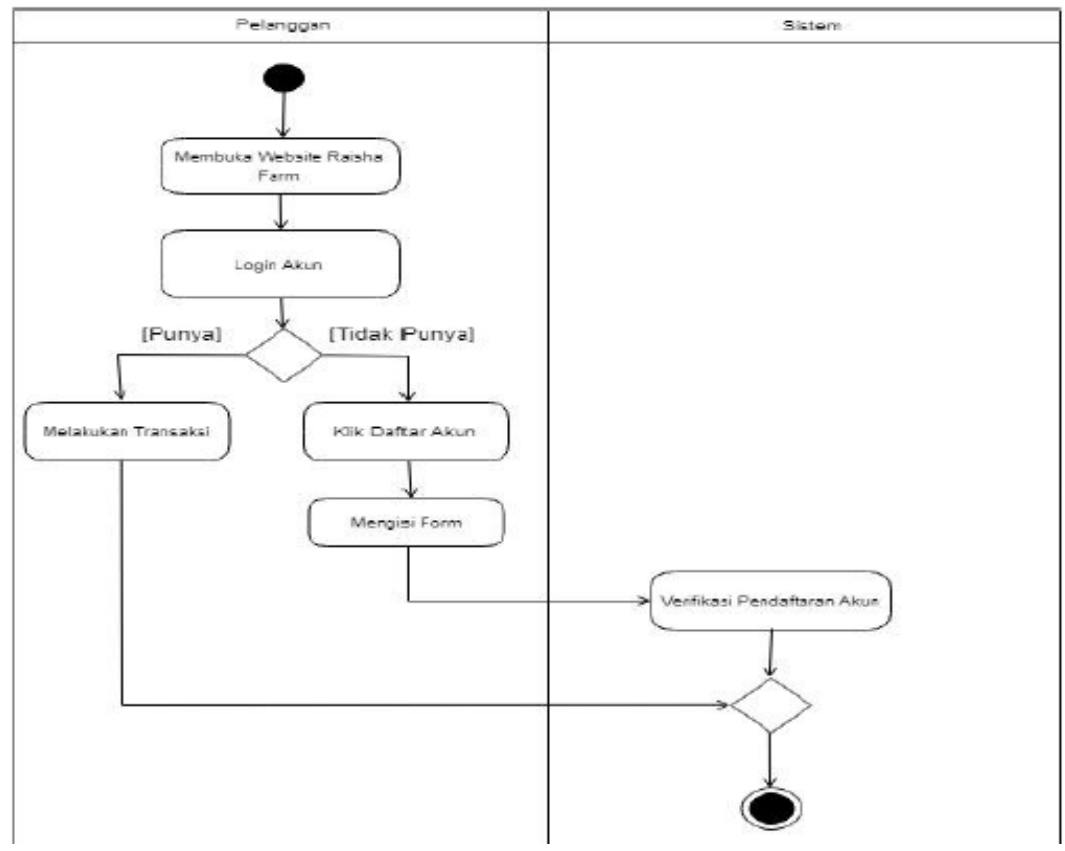

Gambar 2. Activity Diagram Usulan Proses Login

\section{b. Proses Pemesanan Qurban}

Pegawai menginput list harga produk di website raisha farm. Lalu pelanggan membuka website raisha farm dan melihat-melihat produk. Jika pelanggan tertarik maka pelanggan melakukan pemesanan dengan mengklik menu pemesanan qurban. Kemudian pelanggan menginput pemesanan qurban yang dipilih untuk dilakukan pembayaran. Activity Diagram pemesanan qurban ditunjukan pada Gambar 3:

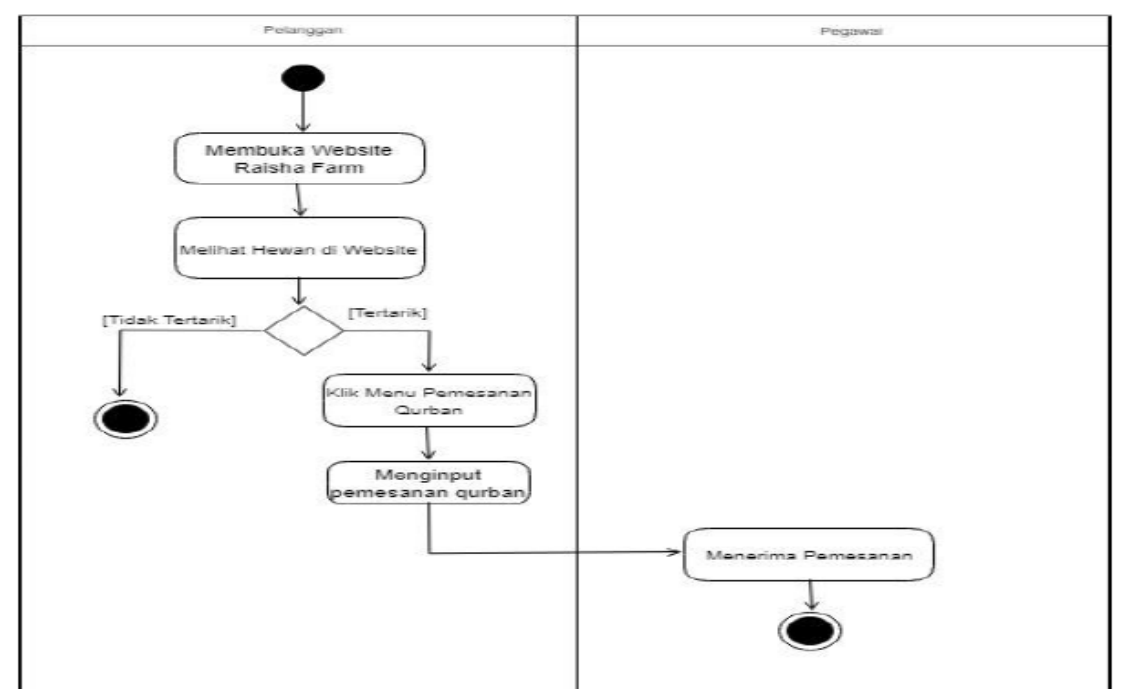

Gambar 3. Proses Pemesanan Hewan Qurban 


\section{c. Proses Pemesanan Aqiqah}

Pegawai menginput list harga produk di website raisha farm. Lalu pelanggan membuka website raisha farm dan melihat-melihat produk. Jika pelanggan tertarik maka pelanggan melakukan pemesanan dengan mengklik menu pemesanan aqiqah. Kemudian masuk kedalam menu pemesanan aqiqah yang terdapat paket aqiqah, pelanggan menginput pemesanan aqiqah sesuai paket yang dipilih untuk dilakukan pembayaran. Activity Diagram proses pemesanan aqiqah ditunjukan pada Gambar 4:

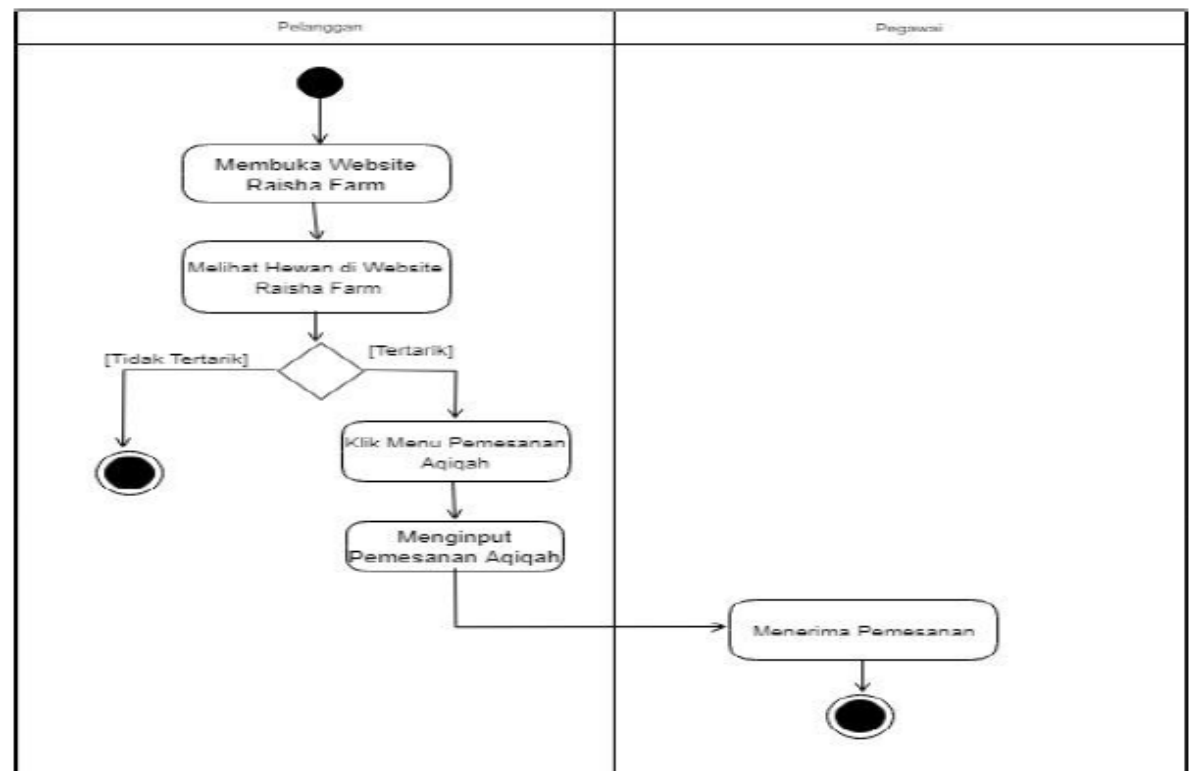

Gambar 4. Proses Pemesanan Hewan Aqiqah

\section{d. Proses Pembayaran Qurban dan Aqiqah}

Pelanggan melakukan pembayaran ke rekening bank yang terdapat pada website. Setelah transfer pelanggan mengupload foto bukti transfer di menu pembayaran Aqiqah dan Qurban. Jika bukti transfer sesuai dengan nominal harga yang ditentukan maka pegawai akan menginput surat jalan. Jika tidak sesuai akan menginfokan ke pelanggan bahwa pembayaran tidak sesuai dengan nominal. Kemudian pegawai memulai proses produksi. Activity Diagram proses pembayaran qurban dan aqiqah ditunjukan pada Gambar 5:

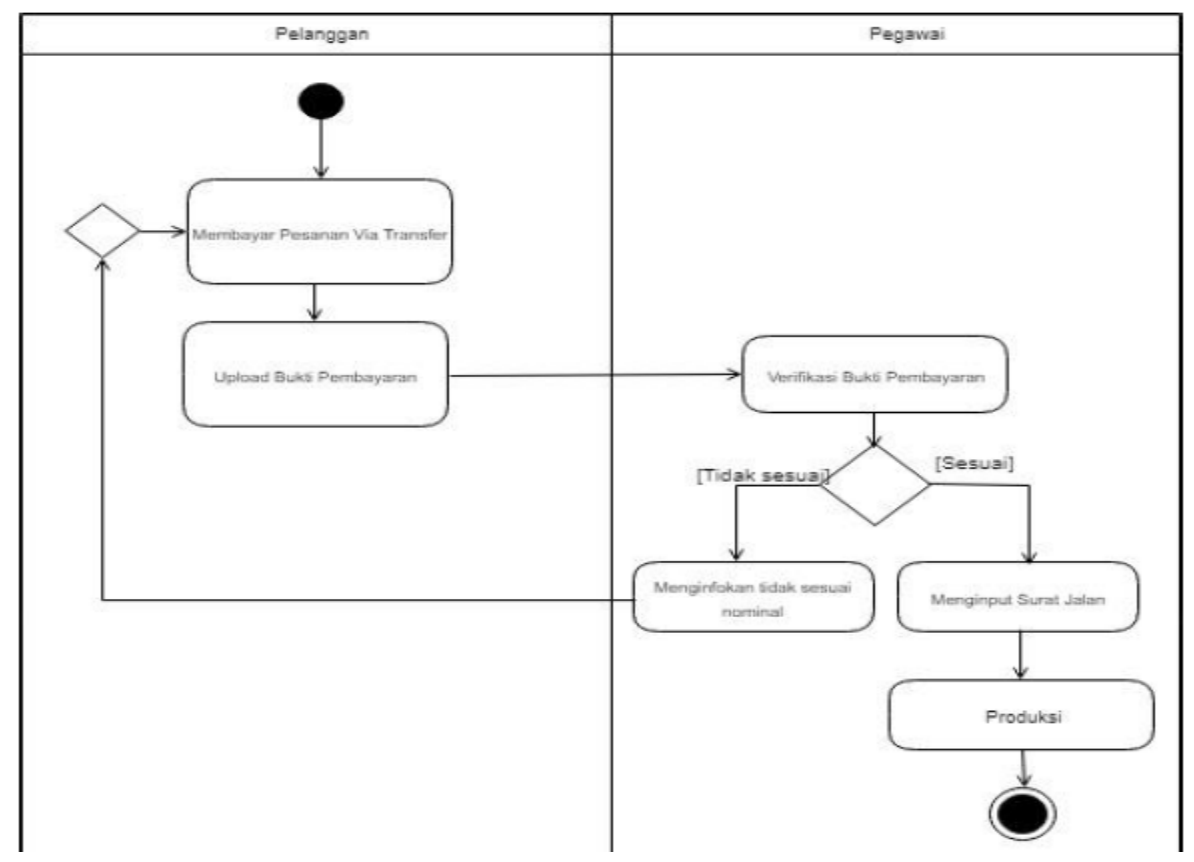

Gambar 5. Proses Pembayaran Qurban dan Aqiqah 


\section{e. Proses Pengiriman}

Pegawai mengecek pesanan sebelum proses pengiriman, setelah itu mencetak Surat Jalan. Kemudian pegawai menyerahkan pesanan serta surat jalan kepada bagian kurir. Bagian kurir menerima surat jalan dan pesanan, lalu bagian kurir mengecek Surat Jalan sesuai pesanan. Jika sesuai bagian kurir akan mengirim pesanan ke rumah pelanggan tersebut. Pegawai akan mengubah status pengiriman, kemudian pelanggan akan menerima pesanan. Activity Diagram proses pengiriman ditunjukan pada Gambar 6:

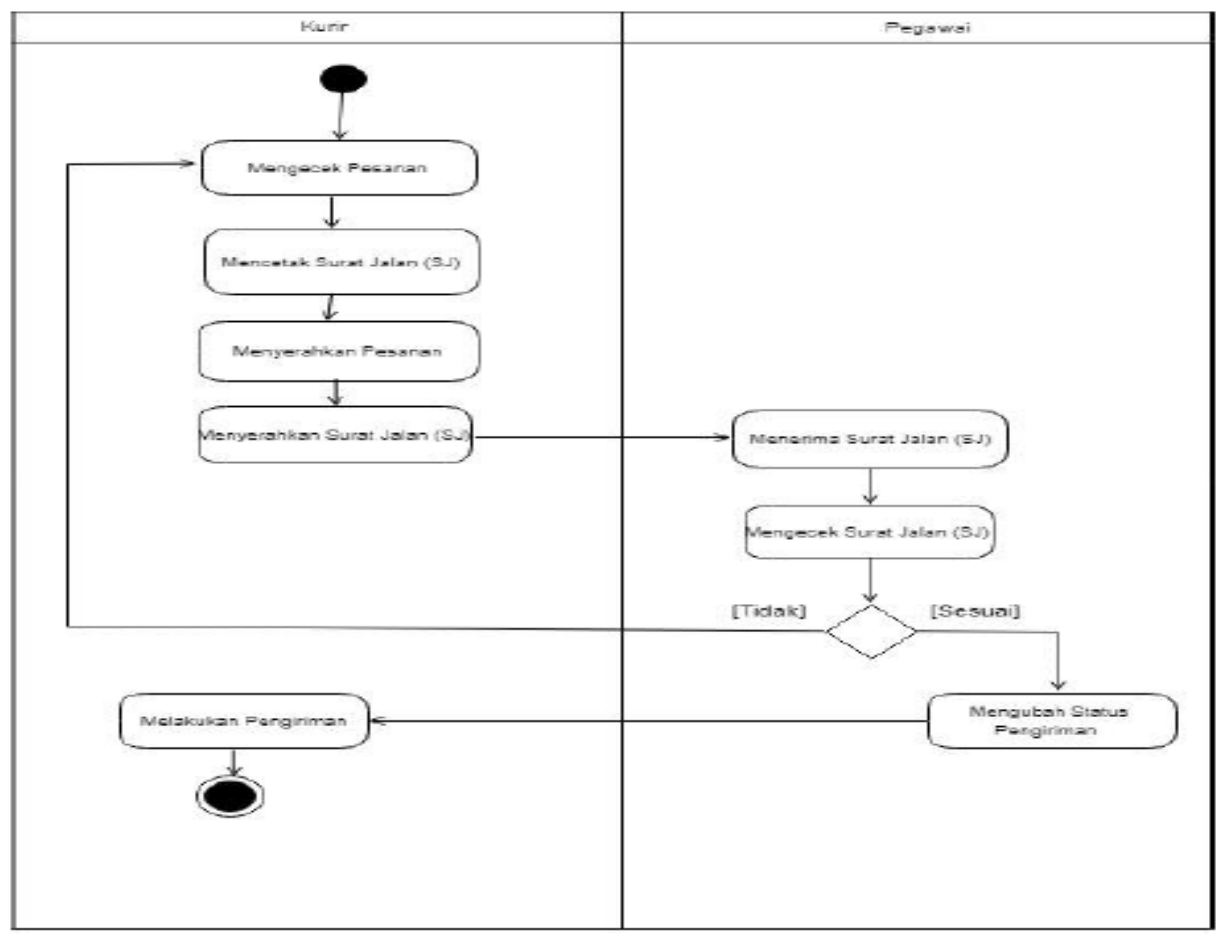

Gambar 6. Proses Pengiriman Qurban dan Aqiqah

\section{f. Proses Cetak Laporan}

Pegawai mengklik menu Cetak Laporan. Kemudian pegawai memilih laporan yang ingin di cetak, klik cetak untuk mencetak laporan yang sudah dipilih untuk dilaporkan kepada pemilik Raisha Farm. Setelah itu diberikan kepada pemilik Raisha Farm. Activity Diagram proses pengiriman ditunjukan pada Gambar 7:

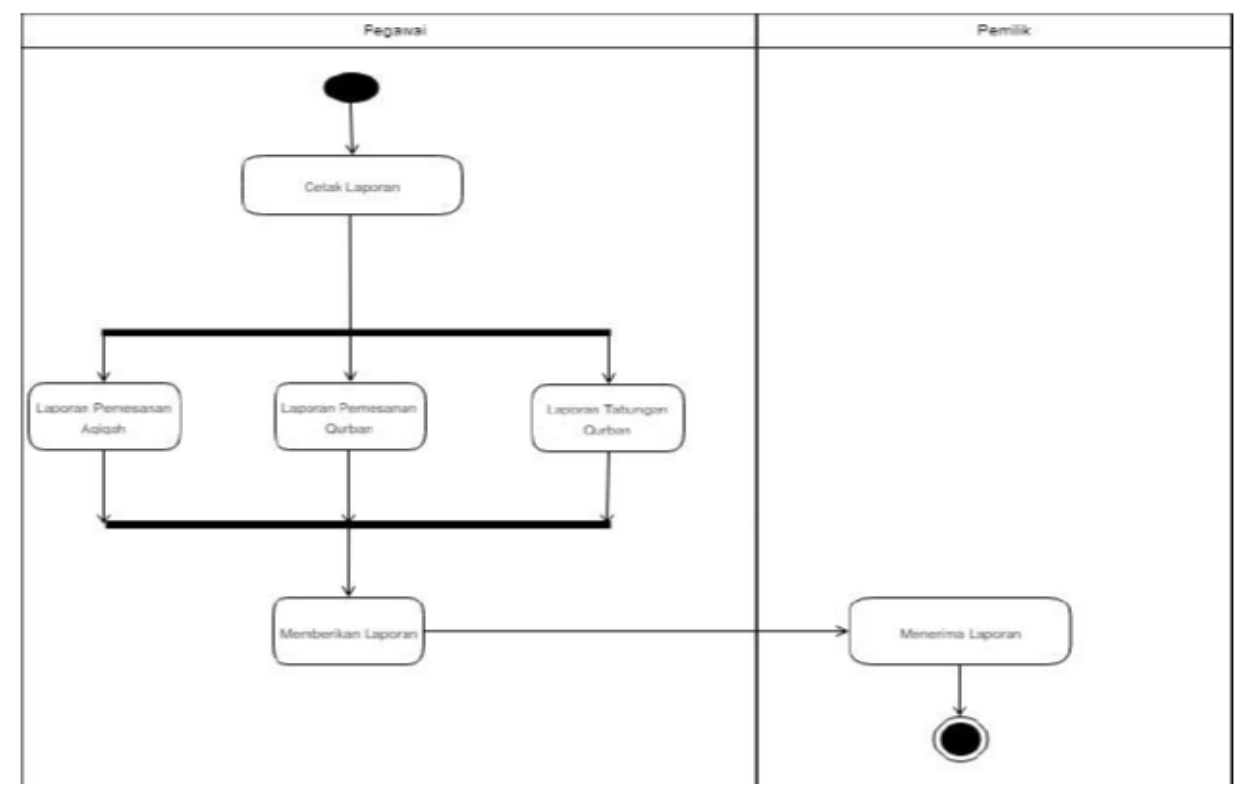

Gambar 7. Proses Pembuatan Laporan 


\subsection{Use case Diagram}

Definisi Use Case yaitu hubungan antara manusia dengan sistem yang dibangun[4]. Definisi lain Use Case yaitu menjelaskan siapa pengguna sistem dan cara menggunakan agar saling terhubung [9]. Use Case Diagram transaksi ini pelanggan dapat entry pembelian Qurbam, entry pemesanan Aqiqah dan Upload Bukti Pembayaran sedangkan pegawai dapat Cetak Bukti Pembayaran yang ditunjukan pada Gambar 8:

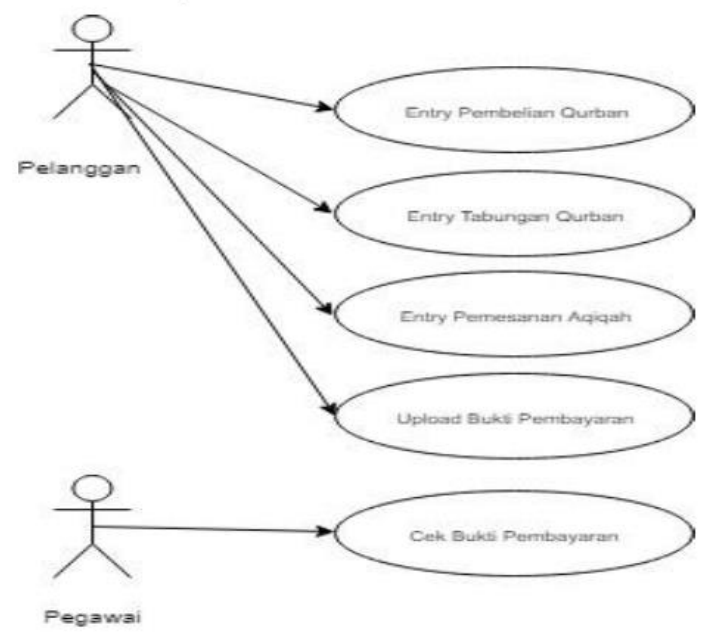

Gambar 8. Use Case Diagram transaksi

\subsection{Logical Record Structure (LRS)}

LRS adalah himpunan antar entitas yang menggambarkan struktur record table [4][10]. Rancangan basis data untuk memodelkan penjualan pada Raisha Farm ditransformasikan kedalam LRS ditunjukan pada Gambar 6. Dari analisa yang dilakukan akan digunakan 9 entitas yang digunakan peneliti.

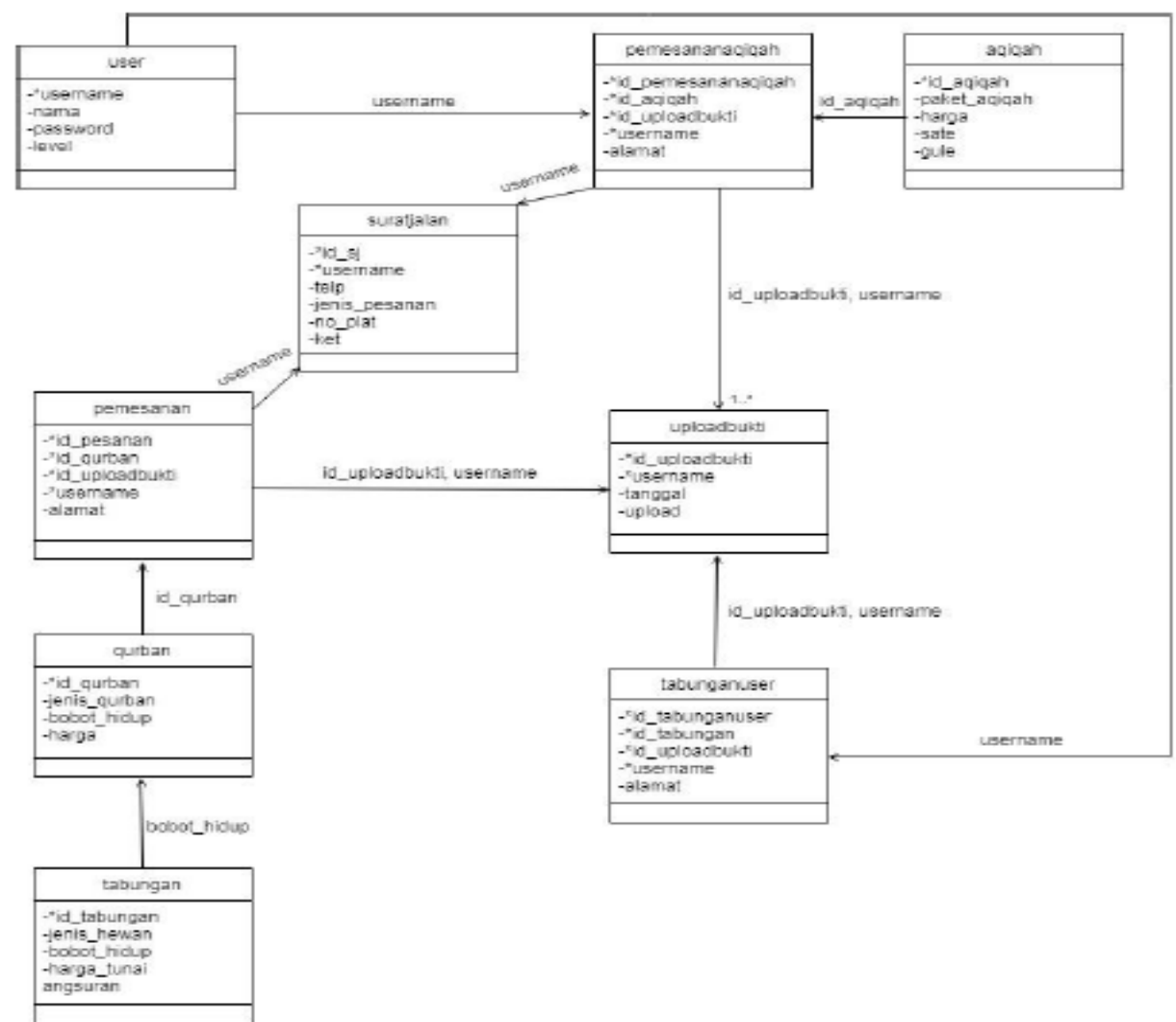

Gambar 9. Logical Record Structure 


\subsection{Desain GUI}

Antar muka yang ditampilkan antara komputer dengan penggunanya dalam bentuk gambar[4][11], Struktur tampilan pada Raisha Farm dibagi menjadi 2 yaitu:

a. Struktur Menu Back End

Struktur tampilan Back End pada Raisha Farm ketika admin/pegawai mengakses menu ini maka pegawai dapat membuka menu data qurban, Data Aqiqah, Surat Jalan, Pesanan aqiqah dan qurban yang dilakukan oleh pelanggan serta mencetak laporan. Menu Back End pada Raisha Farm ditunjukan pada Gambar 10:

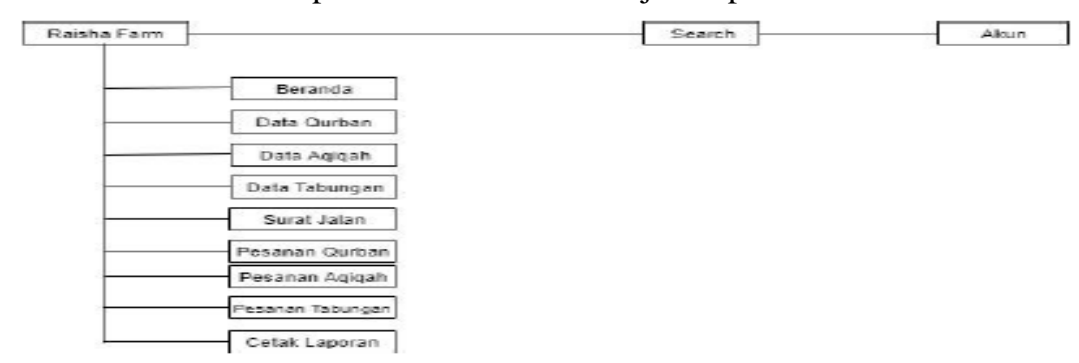

Gambar 10. Struktur Menu Front End

b. Rancangan Layar Pengiriman/Surat Jalan

Pada Rancangan Layar pengiriman/ Surat Jalan admin/pegawai dapat melihat pesanan hewan qurban dan aqiqah yang telah terkirim atau belum. Rancangan Layar pengiriman atau Surat Jalan pada Raisha Farm ditunjukan pada Gambar 11:

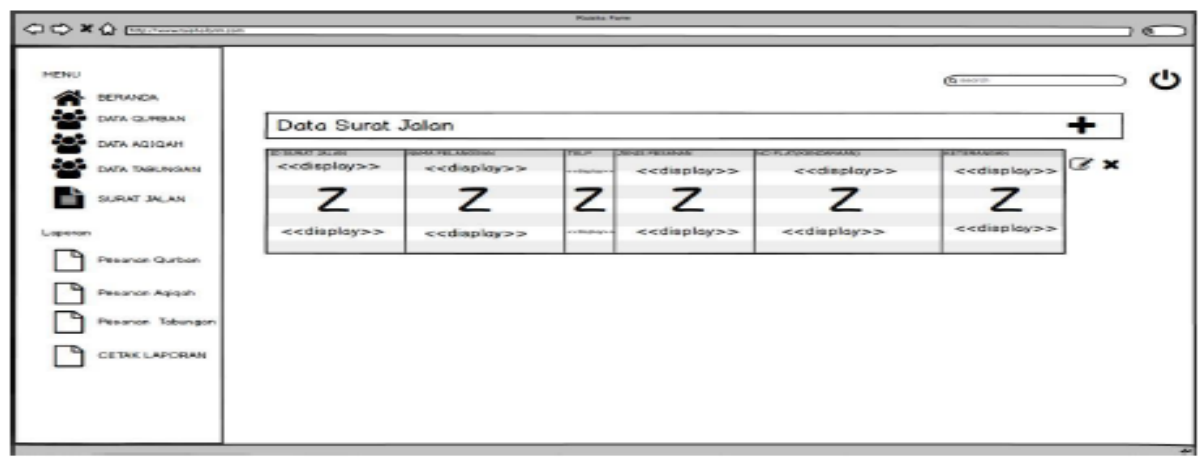

Gambar 11. Rancangan Layar Pengiriman

\subsection{Evaluasi}

Tahapan Evaluasi yaitu dengan melakukan pengujian menggunakan Black-Box Testing yaitu dengan menginputkan pada program, dari inputan itu dapat dilihat apakah program yang dibuat terdapat error dan isian yang masih kosong akan memberikan pesan agar field di isi lengkap[4]. Tujuan dilaksanakan evaluasi adalah mengetahui keberhasilan sistem yang sedang di bangun. Hasil Pengujian Black-Box Testing ditujukan pada Table 1:

Tabel 1. Hasil Pengujian

\begin{tabular}{|l|l|l|l|}
\multicolumn{1}{|c|}{ Pengujian } & \multicolumn{1}{c|}{ Harapan } & \multicolumn{1}{c|}{ Hasil } & \multicolumn{1}{c|}{ Kesimpulan } \\
\hline $\begin{array}{l}\text { Login berdasarkan User } \\
\text { dan password yang telah } \\
\text { terdaftar }\end{array}$ & $\begin{array}{l}\text { Pelanggan berhasil login, } \\
\text { pelanggan Login Berhasil } \\
\text { memesan baik Qurban } \\
\text { maupun Aqiqah }\end{array}$ & & Berhasil \\
\hline $\begin{array}{l}\text { Entry Pemesanan Hewan } \\
\text { Qurban }\end{array}$ & $\begin{array}{l}\text { Pelangaan dapat memilih } \\
\text { hewan qurban yang ingin } \\
\text { dipesan dan sistem dapat } \\
\text { menampilkan biaya yang } \\
\text { akan dibayar. }\end{array}$ & $\begin{array}{l}\text { Sistem } \\
\text { memberikan informasi } \\
\text { pemesanan Qurban } \\
\text { kepada admin lalu } \\
\text { menampilkan jumlah } \\
\text { yang akan di bayarkan }\end{array}$ & Berhasil \\
\hline
\end{tabular}


available online at http://jom.fti.budiluhur.ac.id/index.php/IDEALIS/index

\begin{tabular}{|c|c|c|c|}
\hline $\begin{array}{l}\text { Entry Pemesanan Hewan } \\
\text { Aqiqah }\end{array}$ & $\begin{array}{l}\text { Pelangaan dapat memilih } \\
\text { Paket Aqiqah yang ingin } \\
\text { dipesan dan sistem dapat } \\
\text { menampilkan biaya yang } \\
\text { akan dibayar. }\end{array}$ & $\begin{array}{l}\text { Sistem dapat } \\
\text { memberikan informasi } \\
\text { pemesanan Aqiqah } \\
\text { kepada admin lalu } \\
\text { menampilkan jumlah } \\
\text { yang akan di bayarkan }\end{array}$ & Berhasil \\
\hline Entri Bukti Pembayaran & $\begin{array}{lr}\text { Pelanggan } & \text { dapat } \\
\text { mengupload } & \text { bukti } \\
\text { pembayaran } & \text { melalui } \\
\text { entry data pembayaran }\end{array}$ & $\begin{array}{l}\text { Sistem } \\
\text { memberikan informasi } \\
\text { bukti bayar dan admin } \\
\text { dapat melihat bukti } \\
\text { pembayaran } \\
\text { pelanggan }\end{array}$ & Berhasil \\
\hline
\end{tabular}

Berdasarkan hasil evaluasi pada table diatas, tidak terdapat eor sistem, sehingga dapat disimpulkan bahsa sistem dapat digunakan sebagai mana mestinya.

\section{KESIMPULAN}

Berdasarkan analisis yang telah dilakukan, maka dapat disimpulkan bahwa (a) Dengan dibuatkan aplikasi penjualan hewan qurban dan aqiqah secara online sangat membantu pihak Raisha Farm dalam meningkatkan hasil penjualan, karena hasil penjualan tidak hanya didapat dari penjualan secara langsung tetapi dapat dilakukan dengan online melalui website. (b) Dengan adanya sistem ini membantu raisha farm dalam mengelola data menjadi lebih efektif dan akurat. (c) Dengan adanya sistem secara online diharapkan dapat memperluas area penjualan Qurban Dan Aqiqah pada Raisha Farm. (d) Informasi detil terkait hewan qurban maupun aqiqah dan Ketersediaan Hewan mempermudah pelanggan dalam melakukan pemesanan.

\section{DAFTAR PUSTAKA}

[1] R. Pakaya, A. R. Tapate, and S. Suleman, "Perancangan Aplikasi Penjualan Hewan Ternak Untuk Qurban Dan Aqiqah Dengan Metode Unified Modeling Language (UML)", Jurnal Technopreneur, vol.8, no.1, pp.31-40, 2020.

[2] A. Suresti and R. Wati, "Strategi Pengembangan Usaha Peternakan Sapi Potong di Kabupaten Pesisir Selatan", Jurnal Peternakan Indonesia., vol.14, no.1, pp. 249-262, 2013.

[3] R. Waluyo, Z. Karini, and K. A. Purnomo, "Perancang Aplikasi M-Commerce Berbasis Android Sebagai Media Informasi dan Penjualan Kambing”, Jurnal CoreIT, vol.4, no.1, pp.1-7, 2018.

[4] Wulandari, P. Dwi, P. Nugroho, and F. Ramadhan, "Rancangan Sistem Informasi Penyewaan Bus Dengan Pendekatan Electronic Customer Relationship", Jurnal IDEALIS, vol.4, no.1, pp.1-10, 2021.

[5] H. Zhafar and B. D. Andah, "Penerapan Electronic Customer Relationship Management Terhadap Upaya Peningkatan Kepuasan Dan Loyalitas Pelanggan Ahass Sinar Makmur Sentosa Pada Divisi Perawatan Motor (H2)", Jurnal IDEALIS, vol.1, no.1, pp.461-467, 2018.

[6] I. Oktaviani, and R. S. Lilik, "Sistem informasi penjualan kambing dan pemesanan aqiqah berbasis E-commerce Pada UKM Hasanah", Jurnal Informa Politeknik Indonusa Surakarta, vol. 3, no.2, pp.23-29, 2017.

[7] D. Anggoro, R. Budiman, R. A. Febrian, and Y. G. Kumara, "Rancangan Sistem Informasi Penjualan Berbasis Web Pada Lookass Lookiss Art Work Garage", Jurnal IDEALIS, vol.4, no.1, pp.31-36, 2021.

[8] S. Khoiriyah and R. M. Mutu, "Analisis dan Perancangan Sistem Perhitungan Insentif Marketing Trade Menggunakan Sistem Remunerasi”, EDUMATIC Jurnal Pendidikan Informatika, vol.3, no.2, pp.99-108, 2019.

[9] Sholiq, Analisis dan Perancangan Berorientasi Objek. Yogyakarta: Graha Ilmu, 2010.

[10] A. Sukmaindrayana and R. Sidik, “Aplikasi Grosir Pada Toko Rsidik Bungursari Tasikmalaya,” JUMIKA, vol.4, no.2, pp.31-40, 2017.

[11] D. Martin, “18 Konsep Dasar Graphic User Interface (GUI)! Desainer Wajib Tahu,” 2020. [Online]. Available: https://www.techfor.id/18konsep-dasar-graphic-user-interface-gui-desainer-wajib-tahu/ 